\title{
Prevalence of Glaucoma in Hospitalized Older Adults with Alzheimer's Disease
}

\author{
Andrée-Anne Pelletier, Marie-Ève Théorêt, Tanguy Boutin, Marie-Jeanne \\ Kergoat, Fadi Massoud, Judith Latour, Céline Chayer, Hélène Kergoat
}

\begin{abstract}
Objective: To determine the prevalence of glaucoma in older adults with dementia of the Alzheimer's type (DAT). Methods: Retrospective chart review: The prevalence of glaucoma was determined in older adults with a diagnosis of DAT or mixed dementia (DAT with vascular contribution) admitted to the geriatric and neurology units of the Centre hospitalier de l'Université de Montréal and the Hôpital Maisonneuve-Rosemont between April 2008 and April 2009 (n=220; DAT group). They were matched for age and date of hospitalisation to the first 220 individuals without dementia (control group) recruited from other medical units in the same hospitals: gastroenterology, internal medicine or cardiology. A diagnosis of glaucoma was deemed positive if recorded in the chart or if there was a medication compatible with this diagnosis. Chi-square tests were used for between-group comparisons. Results: Subjects' age ranged from 66 to 101 years. The prevalence of glaucoma was $6.8 \%$ in our study population $(n=30 / 440)$. Glaucoma was significantly more prevalent in the DAT group $(n=21 ; 9.5 \%)$ than in the control group $(n=9 ; 4.1 \%)\left[\chi_{1}^{2}=5.15 ; p=0.023\right]$. Conclusions: The prevalence of glaucoma was higher in a group of older adults with DAT than in a comparable control group. These results underscore the importance of providing regular eyecare for persons affected by DAT.
\end{abstract}

RÉSUMÉ: Prévalence du glaucome chez des personnes âgées hospitalisées atteintes de la maladie d'Alzheimer. Objectif : Déterminer la prévalence du glaucome chez des personnes âgées atteintes de démence de type Alzheimer (DTA). Méthode : Revue rétrospective de dossiers: La prévalence du glaucome a été déterminée chez des personnes âgées, chez qui un diagnostic de DTA ou de démence mixte (DTA avec composante vasculaire) avait été posé, admis à l'unité gériatrique ou à l'unité neurologique du Centre hospitalier de l'Université de Montréal ou à l'Hôpital Maisonneuve-Rosemont entre avril 2008 et avril 2009 (groupe DTA n = 220). Ils ont été appariés pour l'âge et la date d'hospitalisation aux 220 premiers individus sans démence (groupe témoin) admis dans d'autres unités médicales des mêmes hôpitaux, soit la gastroentérologie, la médecine interne ou la cardiologie. Le diagnostic de glaucome a été considéré comme positif s'il avait été inscrit au dossier ou ou s'il y avait prise de médication compatible avec ce diagnostic. Nous avons utilisé le chi-carré pour comparer les groupes. Résultats : L'âge des sujets variait de 66 à 101 ans. La prévalence du glaucome était de $6,8 \%$ dans la population à l'étude $(\mathrm{n}=30 / 440)$. La prévalence du glaucome était significativement plus élevée dans le groupe atteint de DTA $(n=21 ; 9,5 \%)$ que dans le groupe témoin $(n=9 ; 4,1 \%)\left[\chi_{1}^{2}=5,15 ; p=0,023\right]$. Conclusion : La prévalence du glaucome était plus élevée dans un groupe de personnes âgées atteintes de DTA que dans un groupe témoin comparable. Ces résultats soulignent l'importance de fournir des soins oculovisuels réguliers aux individus atteints de DTA.

Can J Neurol Sci. 2014; 41: 206-209

Statistics indicate that $14 \%$ of the Canadian population was 65 years-of-age and older in $2009^{1}$, and that this proportion will nearly double by the year $2036^{2}$. The Canadian Study of Health and Aging (CSHA) further indicated that $8 \%$ of Canadians 65 years-of-age and older, and $33 \%$ of those 85 years-old (y.o.) and older suffer from dementia ${ }^{3}$. Dementia of the Alzheimer's type (DAT) is the most common type of dementia in older adults ${ }^{3}$, and is often found in combination with vascular cerebral lesions, a condition referred to as mixed dementia.

Canadian statistics also indicate that the prevalence of ocular diseases increases with age, with glaucoma affecting $6 \%$ of Canadians 65 y.o. and older ${ }^{4}$. Glaucoma is the second leading cause of blindness worldwide ${ }^{5}$, and represents the first irreversible cause of vision loss in industrialised countries ${ }^{6}$.

Many studies have reported similarities between DAT and open-angle glaucoma (OAG), although controversy remains as to whether or not there is a potential link between the two diseases. Both DAT and glaucoma are more prevalent with age and in women ${ }^{7,8}$. Whereas a loss of retinal ganglion cells and their axons, as well as a thinning of the retinal nerve fiber layer are well described in glaucoma ${ }^{9}$, these changes have also been reported in DAT ${ }^{10,11}$. This has been correlated with functional $\operatorname{loss}^{12,13}$ although it is not universally accepted ${ }^{14-16}$. The apolipoprotein E (ApoE) 4 allele is an important genetic risk

From the School of Optometry (AAP, MET, HK), Faculty of Medicine (TB, MJK, FM, JL, CC), Institut universitaire de gériatrie de Montréal (MJK, FM, JL, CC, HK), Centre hospitalier de l'Université de Montréal (FM, JL, CC), Hôpital Maisonneuve-Rosemont

(CC), l'Université de Montréal, Montréal, Québec, Canada.

Received July 19, 2013. Final Revisions Submitted September 17, 2013. Correspondence to: Hélène Kergoat, School of Optometry, University of Montreal, Succ. Centre-Ville; Montréal, Québec, H3C 3J7, Canada.

Email: helene.kergoat@umontreal.ca 
factor for $\mathrm{DAT}^{17}$ and it has also been positively associated with $\mathrm{OAG}^{18,19}$. However, this remains a controversial issue ${ }^{20-22}$ as no difference in the percentage of individuals having the ApoE4 allele and suffering from DAT and glaucoma was found compared to those having DAT without glaucoma ${ }^{23}$.

Studies using experimental animal models of ocular hypertension or glaucoma have found an increased level of amyloid beta $(A B)$, a protein found in senile plaques of the brain of individuals with DAT, in the retinal ganglion cells and optic nerve ${ }^{24,25}$. Moreover, the presence of abnormal tau protein molecules, which are found in the brain of individuals with DAT, was found in the retinal tissue of patients with glaucoma ${ }^{26}$. Wostyn $^{27}$ has suggested that a decreased cerebrospinal fluid pressure (CSFP), found in some patients with DAT, could be a potential mechanism leading to glaucoma in those individuals. This hypothesis is derived from results showing that both an elevated intraocular pressure (IOP) or a reduced CSFP was found in glaucoma patients ${ }^{28}$, and if found alone or in combination can lead to optic nerve damage ${ }^{28}$. Finally, although some post-mortem ${ }^{29}$ and clinical studies have concluded that individuals with DAT were at greater risk of developing glaucoma ${ }^{23,30-32}$, epidemiological studies have failed to confirm such results ${ }^{33-35}$.

In view of these controversial results and in the context of global aging of the population, it is of prime importance to verify if there is an association between DAT and glaucoma. Therefore, the objective of this study was to determine if glaucoma is more prevalent in older individuals with DAT compared with agematched controls, in a Canadian population.

\section{METHODS}

\section{Hospitals}

This study was conducted at the Centre hospitalier de l'Université de Montréal (CHUM) and the Hôpital Maisonneuve-Rosemont (HMR). These hospitals are both large academic centers where it was possible to identify a target number of case subjects and the corresponding number of agematched controls within the same period of hospitalisation. This study was approved by the Research Ethics Committees of the CHUM and the HMR.

\section{Clinical chart review}

We retrospectively reviewed all charts of patients 65 y.o. and older, admitted to these hospitals between April 2008 and April 2009 in the geriatric or neurology units. Case subjects had to have a diagnosis of DAT or mixed dementia given either before or during the period of hospitalisation. In these units, special attention is given to cognitive impairment. Patients with a presumed diagnosis of dementia are clinically evaluated to insure that the diagnosis is valid according to published criteria $^{36,37}$. In patients without a diagnosis of dementia, cognitive evaluation on history and physical examination is done routinely. Exclusion criteria for cases were: other form of dementia, massive stroke, and long-term use of corticosteroids (because of its potential effect on intraocular pressure). The control subjects were matched for age and period of hospitalisation ( \pm 3 months) from the cardiology, gastroenterology or internal medicine units of the same hospital on a one-to-one basis. Control subjects had to be free of any type of dementia, massive stroke or long-term use of corticosteroids. Data collection included: date of birth, age, sex, date of hospitalisation, reason for admission, Mini-Mental State Examination (MMSE) score, presence or absence of dementia, presence or absence of glaucoma, and medication linked to dementia or glaucoma. The data were entered in FileMaker Pro (File Maker, Inc., Santa Clara, CA) on a portable Macintosh computer. The data were interrogated and analysed directly in FileMaker Pro or after exportation in Excel.

\section{Statistical Analyses}

Mean, standard deviation and percentage were calculated. Differences in prevalence of glaucoma between groups (DAT vs control groups) were obtained using Chi-square tests. An alpha level of 0.05 was selected for statistical significance.

\section{RESULTS}

Over the one year study period, 220 patients fulfilling our inclusion/exclusion criteria were admitted to the hospital and were diagnosed with DAT or mixed dementia. These patients were age-matched on a one-to-one basis with control subjects admitted to the same hospital within the same period of time. Each of these 440 clinical charts were thoroughly reviewed to collect the study data. Of the 220 case subjects, $65.5 \%$ took a medication consistent with the disease (donepezil, rivastigmine, galantamine or memantine). Overall, $71.4 \%$ of these case subjects were females. Their ages varied from 66 to 101 y.o., with a mean of $83.7 \pm 6.3$ years. A MMSE score was available for 181 case subjects and varied from 2 to 29 , with a mean of $19.6 \pm 5.6$. Amongst the 220 control subjects without dementia, $65.0 \%$ were females and their age varied from 66 to 100 y.o. with a mean of $83.6 \pm 7.6$ years. A MMSE score was rarely available for these control subjects. However, none of them had or received a diagnosis of dementia during hospitalisation or was on any medication used against dementia.

Altogether, 30 of the 440 subjects were classified as having glaucoma, based on self-reported history, medication compatible with the diagnosis or results of an eye exam (see Table). All controls with the diagnosis were on antiglaucoma medication while six DAT subjects with the disease were not, including one for whom the results of an eye exam was in the chart. The overall prevalence of glaucoma was $6.8 \%$ for our study population. Of those 30 subjects, 21 were from the case group and nine from the control group, representing respectively a prevalence of glaucoma of $9.5 \%$ vs $4.1 \%\left(\chi_{1}^{2}=5.15 ; p=0.023\right)$.

\section{Discussion}

To our knowledge, no study similar to the one presented here has been conducted in the Canadian population. Our data support the hypothesis that the prevalence of glaucoma is increased in individuals with DAT. Our results are in agreement with previous data from Germany and Japan which have found prevalence of glaucoma of $25.9 \%$ vs $5.2 \%{ }^{30}, 24.5 \%$ vs $6.5 \%^{31}$ and $23.8 \%$ vs $9.9 \%{ }^{23}$, respectively, in individuals with DAT compared to controls. They have further shown, although in a very small number of individuals, that progression of glaucoma is more severe in individuals with $\mathrm{DAT}^{32}$. It has been 
Table: Summary break down indicating on what basis the subjects were classified as having a diagnosis of glaucoma, and the number of subjects in each category.

\begin{tabular}{l|c|c|c}
\multicolumn{1}{c|}{ Test group } & History & Medication & File \\
\hline DAT & 21 & 15 & 5 \\
\hline Controls & 9 & 9 & 1 \\
\hline DAT $=$ dementia of the Alzheimer's type
\end{tabular}

hypothesized that the optic nerve head in individuals with DAT is less resistant to increased IOP, predisposing the eye to develop glaucoma rather than ocular hypertension ${ }^{30}$.

The main limitations of our study are its retrospective and cross-sectional design. This could lead to underestimation of the prevalence of both glaucoma and dementia. Also, causality and direction of the association cannot be assessed with such a design. The lower prevalence values of glaucoma obtained in our study compared to those cited above might be related to its retrospective nature. Glaucoma develops and progresses insidiously and thus may remain asymptomatic for a while. Therefore, it is possible that glaucoma was present, but undiagnosed, in more study subjects in either group, than found by chart review. However, it is unlikely that this would have affected significantly the study outcomes since the prevalence of glaucoma was 2.35 times higher in the case vs control groups, and that there is no reason to believe that glaucoma is more recognized in individuals with dementia than in controls. In fact, it is more likely that glaucoma is underestimated in DAT subjects compared to control subjects because individuals with DAT may not be able to report their symptoms as well or to specifically ask for regular eyecare. The type of glaucoma could not always be confirmed by clinical chart. However, in Canada, about $90 \%$ of glaucoma is of the OAG type ${ }^{38}$, which most likely then was the cause of glaucoma in our study subjects. It is also possible that some subjects from the control group had undiagnosed DAT or mixed dementia, and the fact that no control subject was on medication used against dementia does not preclude such diagnoses. However, and in spite of the limitations acknowledged herein, it remains that the combined results of the present study and previous reports, certainly stress the relevance of conducting a well-designed, larger-scale, clinical prospective case-control study to confirm if individuals with DAT are at higher risk of glaucoma.

Despite the study limitations highlighted above, the present results are important and they should, at the least, raise the awareness of all Canadian physicians and eyecare specialists who examine older adults with DAT. First, glaucoma is an insidious disease, potentially leading to blindness, that may remain undetected if an eye exam is not performed. Second, older persons with dementia may not be able to identify, or to express, any changes happening in their vision; alternatively they may not receive eyecare because of other more obvious health issues linked to dementia. Furthermore, with progression of dementia, many of those individuals will eventually be institutionalized. It has been reported that residents in long-term care have less access to eyecare ${ }^{39}$, in Canada as well ${ }^{40}$. Therefore, older residents with dementia having a diagnosis of glaucoma should receive regular eyecare to optimize treatment and preserve their vision. On the other hand, residents with dementia but without a pre-existing diagnosis of glaucoma at the time of admission should receive regular preventative eyecare. This should not be underrated since it is well documented that having combined cognitive and visual deficits places these residents at higher risk of negative consequences ${ }^{41}$, including delirium $^{42}$.

There have been two longitudinal population-based epidemiologic studies evaluating the risk of developing DAT in older individuals having glaucoma, one conducted in Denmark ${ }^{33}$ and one in the United States ${ }^{35}$, that failed to find an increased risk of developing DAT in older individuals with glaucoma. A third longitudinal population-based epidemiologic study did not find that individuals with normal tension glaucoma (NTG) were at higher risk of developing DAT ${ }^{34}$. This latter study had focused on NTG specifically, with the hypothesis that NTG is a neurodegenerative disease while OAG associated with increased IOP might have another origin. It is important to note that these epidemiologic studies focused on the risk of developing DAT in individuals with glaucoma while the clinical studies have indicated that there was an increased prevalence of glaucoma in individuals with DAT. There might be risk factors in DAT placing these individuals at increased risk of developing glaucoma, while individuals with glaucoma may not have specific risk factors for DAT. Thus, future longitudinal epidemiologic studies should focus on the risk of developing glaucoma in patients with DAT. Although DAT and OAG seem to share common genetic and pathophysiological features, they may also present important differences making the eye of an individual with DAT more susceptible to glaucoma, without making an individual with glaucoma more at risk for DAT.

\section{CONCLUSION}

In conclusion, our results indicate that the prevalence of glaucoma is increased in individuals having DAT. It underscores the importance of conducting a large-scale prospective study able to confirm these results and generalize them to the population. If a consensus is reached linking DAT and glaucoma, best clinical practices will have to ensure that older adults with DAT are properly screened, followed-up and treated for glaucoma.

\section{ACKNOWLEDGEMENTS}

The authors thank Andrée Séguin and France Bertrand from the archive services at the Centre hospitalier de l'Université de 
Montréal, pavilion Notre-Dame and the Hôpital MaisonneuveRosemont for their help with handling the clinical charts.

\section{GRANTS}

Institut Universitaire de Gériatrie de Montréal-Comité Aviseur pour la Recherche Clinique and Fonds de développement pour l'enseignement et la recherche clinique de l'École d'optométrie de l'Université de Montréal.

\section{REFERENCES}

1. Population and demography. Statistics Canada, 2010. Canada Year Book 2010. Catalogue no. 11-402-X. p. 315. Available from: http://www.statcan.gc.ca/pub/11-402-x/2010000/pdf/ population-eng.pdf.

2. Population projections $1990-2011$ based on recent changes in fertility levels and revised immigration targets (cat no 91-520), Statistics Canada, Ottawa, 1989.

3. Canadian study of health and aging. The Canadian study of health and aging: study methods and prevalence of dementia in Canada. Can Med Assoc J. 1994;150:899-914.

4. Millar WJ. Problèmes de vision chez les personnes âgées, Rapports sur la santé, vol. 16, no 1, octobre 2004 Statistique Canada, no 82-003 au catalogue p. 49-54.

5. World Health Organization. Prevention of blindness and visual impairment. Accessed on July 16, 2013. Available from: http://www.who.int/blindness/causes/en/

6. Resnikoff S, Pascolini D, Etaya'ale D, et al. Global data on visual impairment in the year 2002. Bull World Health Organ. 2004; 82:844-51.

7. Shiose Y, Kitazawa Y, Tsukahara S, et al. Epidemiology of glaucoma in Japan: a nationwide glaucoma survey. Jpn J Ophthalmol. 1991;35:133-55.

8. Henderson VW. The epidemiology of estrogen replacement therapy and Alzheimer's disease. Neurology. 1997;48:27-35.

9. Quigley HA. Glaucoma. Lancet. 2011;377:1367-77.

10. Hinton DR, Sadun AA, Blanks JC, Miller CA. Optic-nerve degeneration in Alzheimer's disease. N Engl J Med. 1986;315: 485-7.

11. Blanks JC, Hinton DR, Sadun AA, Miller CA. Retinal ganglion cell degeneration in Alzheimer's disease. Brain Res. 1989;501: 364-72.

12. Trick GL, Barris MC, Bickler-Bluth M. Abnormal pattern electroretinograms in patients with senile dementia of the Alzheimer type. Ann Neurol. 1989;26:226-31.

13. Trick GL, Trick LR, Morris P, Wolf M. Visual field loss in senile dementia of the Alzheimer's type. Neurology. 1995;45:68-74.

14. Curcio CA, Drucker DN. Retinal ganglion cells in Alzheimer's disease and aging. Ann Neurol. 1993;33:248-57.

15. Davies DC, McCoubrie P, McDonald B, Jobst KA. Myelinated axon number in the optic nerve is unaffected by Alzheimer's disease. Br J Ophthalmol. 1995;79:596-600.

16. Kergoat H, Kergoat MJ, Justino L, Chertkow H, Robillard A, Bergman H. Visual retinocortical function in dementia of the Alzheimer type. Gerontology. 2002;48:197-203.

17. Saunders AM, Strittmatter WJ, Schmechel D, et al. Association of apolipoprotein $\mathrm{E}$ allele epsilon 4 with late-onset familial and sporadic Alzheimer's disease. Neurology. 1993;43:1467-72.

18. Vickers JC, Craig JE, Stankovich J, et al. The apolipoprotein e4 gene is associated with elevated risk of normal tension glaucoma. Mol Vis. 2002;8:389-93.

19. Al-Dabbagh NM, Al-Dohayan N, Arfin M, Tariq M. Apolipoprotein E polymorphisms and primary glaucoma in Saudis. Mol Vis. 2009;15:912-9.

20. Lake S, Liverani E, Desai M, et al. Normal tension glaucoma is not associated with the common apolipoprotein $\mathrm{E}$ gene polymorphisms. Br J Ophthalmol. 2004;88:491-3.

21. Ressiniotis T, Griffiths PG, Birch M, Keers S, Chinnery PF. The role of apolipoprotein $\mathrm{E}$ gene polymorphisms in primary openangle glaucoma. Arch Ophthalmol. 2004;122:258-61.
22. Zetterberg M, Tasa G, Palmér MS, et al. Apolipoprotein E polymorphisms in patients with primary open-angle glaucoma. $\mathrm{J}$ Ophthalmol. 2007;143:1059-60.

23. Tamura H, Kawakami H, Kanamoto T, et al. High frequency of open-angle glaucoma in Japanese patients with Alzheimer's disease. J Neurol Sci. 2006;246:79-83.

24. Guo L, Salt TE, Luong V, et al. Targeting amyloid- $B$ in glaucoma treatment. Proc Natl Acad Sci USA. 2007;104:13444-9.

25. Kipfer-Kauer A, McKinnon SJ, Frueh BE, Goldblum D. Distribution of amyloid precursor protein and amyloid- $\beta$ in ocular hypertensive C57BL/6 mouse eyes. Curr Eye Res. 2010;35: 828-34.

26. Gupta N, Fong J, Ang LC, Yucel YH. Retinal tau pathology in human glaucomas. Can J Ophthalmol. 2008;41:53-60.

27. Wostyn P, Audenaert K, De Deyn PP. Alzheimer's disease and glaucoma: Is there a causal relationship? Br J Ophthalmol. 2009; 93:1557-9.

28. Berdahl JP, Allingham RR, Johnson DH. Cerebrospinal fluid pressure is decreased in primary open-angle glaucoma. Ophthalmology. 2008;115:763-8.

29. Chandra V, Bharucha NE, Schoenberg BS. Conditions associated with Alzheimer's disease at death. Case-control study. Neurology. 1986;36:209-11.

30. Bayer AU, Ferrari F, Erb C. High occurrence rate of glaucoma among patients with Alzheimer's disease. Eur Neurol. 2002;47: 165-8.

31. Bayer AU, Keller ON, Ferrari F, Maag KP. Association of glaucoma with neurodegenerative diseases with apoptotic cell death: Alzheimer's disease and Parkinson's disease. Am J Ophthalmol. 2002;133:135-7.

32. Bayer AU, Ferrari F. Severe progression of glaucomatous optic neuropathy in patients with Alzheimer's disease. Eye. 2002;16: 209-12.

33. Kessing LV, Lopez AG, Andersen PK, Kessing SV. No increased risk of developing Alzheimer disease in patients with glaucoma. J Glaucoma. 2007;16:47-51.

34. Bach-Holm D, Kessing SV, Mogensen U, Forman JL, Andersen PK, Kessing LV. Normal tension glaucoma and Alzheimer disease: comorbidity? Acta Ophthalmol. 2012;90:683-5.

35. Ou Y, Grossman DS, Lee PP, Sloan FA. Glaucoma, Alzheimer disease and other dementia: A longitudinal analysis. Ophthalmic Epidemiol. 2012;19:285-92.

36. American Psychiatric Association. DSM-IV-TR 2000. Diagnostic and statistical manual of mental disorders. 4th ed. Washington, DC.

37. McKhann GM, Knopman DS, Chertkow H, et al. The diagnosis of dementia due to Alzheimer's disease: Recommendations from the National Institute on aging-Alzheimer's association workgroups on diagnostic guidelines for Alzheimer's disease. Alzheimers Dement. 2011;7:263-9.

38. The national coalition for vision health. Foundations for a Canadian vision health strategy. 2007;16.

39. Van der Pols JC, Bates CJ, McGraw PV, et al. Visual acuity measurements in a national sample of British elderly people. $\mathrm{Br}$ J Ophthalmol. 2000;84:165-70.

40. Kergoat H, Boisjoly H, Freeman EE, et al. The perceived needs and availability of eye care services for older adults in Quebec nursing homes. Am Acad Optom. 2012; Abstract \# 120036.

41. Lawrence V, Murray J, ffytche D, et al. "Out of sight, out of mind": a qualitative study of visual impairment and dementia from three perspectives. Intern Psychogeriatrics. 2009;21:511-8.

42. Inouye SK, Viscoli CM, Horwitz RI, et al. A predictive model for delirium in hospitalized elderly medical patients based on admission characteristics. Ann Intern Med. 1993;119:474-81. 